Retinal c ells tra nsplanted into the bra in mitigate symptoms of Parkinson's disease. The results of a small study suggest that the implanted cells can partly reverse the motion diffic ulties associated with the neurodegenerative disea se

\title{
Retinal cells alleviate motor symptoms in Parkinson's disease
}

Implants of the levodopa-producing human retinal pigment epithelial (RPE) cells improve motor symptoms in Parkinson's disease (PD) patients. The results were published in a preliminary study in the Archives of Neurdogyin D ecember 2005 and provide a potential new avenue for research searching for therapeutic options for PD .

$P D$ is a degenerative disease in which the dopamineproducing cells die off. D opamine is a neurotransmitter that allows the brain to control and smooth the body's movements, and thus, in PD , patientssuffer tremor, rigidity, postural instability and slowed ability to start and continue movements and can end up paralyzed. The cause is currently unknown and there is no cure. Current treatment for PD involves levodopa medication, which replaces dopamine, to control the symptoms; however, in most patients, its effectiveness decreases over 5 years (or less) and long-term oral treatment can lead to the development of motor fluctuations and dyskinesis.

H uman RPE cells, found in the inner layer of the retina, produce levodopa. Therefore, $\mathrm{N}$ atividad Stover and colleagues looked at the implantation of human RPE cells, which can be isolated from postmortem human eye tissue and grown in culture, into PD patients. Since these cells produce levodopa, RPE cells are therefore an exciting potential alterna- tive therapy for PD, providing new hope for sufferers and clinicians looking for improved therapeutic options and outcomes.

Stover and colleagues report on an open-label pilot study that evaluated the safety and efficacy of unilateral implantation of human RPE cells attached to gelatine microcarriers into the putamen

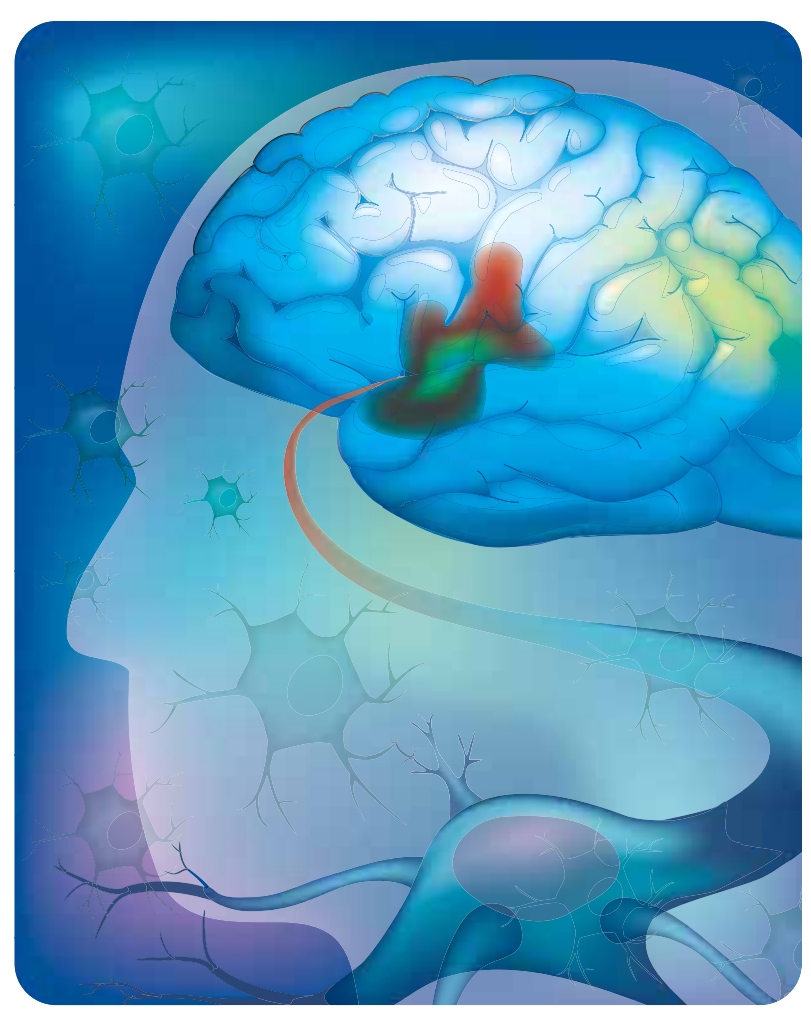

contralateral to the more symptomatic side of six advanced PD patients. These patients received stereotactic intrastriatal cell implantation of approximately 325,000 R PE cells on microcarriers. Efficacy evaluations were carried out at $1,3,6,9,12,15,18$ and 24 months postsurgery; yearly follow-up visits are ongoing and will continue.
Previous results showed that these implants ameliorated the motor deficits in animal models of PD so these initial results in humans are encouraging. "T he implants are well-tolerated", the authors report. "We observed an average improvement of $48 \%$ at 12 months after implantation in the U nified Parkinson's disease Rating Scale motor subscorewith the patient in the off state, which was sustained through 24 months".

Stover and colleagues also observed improvements in activities of daily life, quality of life and motor fluctuations. N 0 off-state dyskinesias were observed. The RPE-gelatin microcarrier implants appear safe and well-tolerated and improved the motor symptoms of these advanced PD patients.

"On the basis of the motor improvement and tolerability observed in this open-label study, a randomized, double-blind, placebo-controlled study has been initiated to more objectively test efficacy and continue to assess safety", conclude the authors.

Previously, researchers have investigated implanting fetal stem cells into the brains of PD patients to restore dopamine production, and this had been viewed as promising. H owever, animal experiments have so far yielded mixed results and preliminary human trials have been disappointing. This new study using RPE cells, which produce levodopa naturally, to reducethe motor deficits in advanced PD patients, offers a fresh alternative to stem cells and potential hope of a beneficial new therapeutic option for PD sufferers. 


\section{in brief}

Enhanced engraftment of hematopoietic stem/progenitor cells by the transient inhibition of an adaptor protein, Lnk.

Takizawa H, Kubo-Akashi C, Nobuhisa I et al. Blood [Epub ahead of print] December 62005.

The authors have identified the functional domains of the intracellular adaptor protein, Lnk, and have developed a dominantnegative mutant which is capable of inhibiting the functions of Lnk expressed endogenously in hematopoietic stem (HS) and progenitor cells, thus potentiating these cells for engraftment. Enhancement of the engrafting potential and expansion capabilities of HS cells can offer the potential to reduce the risks and difficulties currently associated with bone marrow transplantation.

Development of functional human embryonic stem cell-derived neurons in mouse brain

AR M utori, K Nakashima, N Toni, VM Sandler, FH Gage. Proc. Natl Acad. Sci. USA

[Epub, ahead of print] December 132005.

Study demonstrating the ability of human embryonic stem cells to differentiate into functional neural lineages when implanted into the brain ventricles of embryonic mice. The implanted human embryonic stem cells formed mature, active human neurons that were fully integrated into the adult mouse forebrain. This chimeric model presents an opportunity to study human neural development in a live setting, thus facilitating the generation of new models of human neurodegenerative diseases.

Early response of endogenous adult neural progenitor cells to acute spinal cord injury in mice

Yan K, chi L, Xu R, Luo C, Gozal D, Liu R. Stem Cells [Epub, ahead of print] 2005.

Study to examine the early organization, distribution and potential function of adult neural progenitor cells (NPCs) in response to spinal cord injury in transgenic mice. Results demonstrated an enhanced proliferation, migration and neurogenesis from endogenous NPCs in the spinal cord which would suggest a possible role for these cells in restoring spinal cord injury-mediated neuronal cell loss.

\section{Stem cell community tense over $\mathrm{H}$ wang investigation}

Stem cell researchers worldwide are concerned about the potential outcome of an investigation into the validity of Prof. Woo-Suk H wang and colleague's landmark Saience paper published in June 2005. The work of $\mathrm{H}$ wang's team gained international attention as it appears to demonstrate the creation of human embryonic stem (ES) cell lines matching the D N A of patients. This raises the possibility in the clinic of curing patients by cloning their own somatic cells. The research showed that producing such ES cell lines was possibleand that it could al so be performed with a requirement for relatively few donated oocytes per cell line.

H owever, a major ethical issue arose when $\mathrm{H}$ wang admitted that two of his subordinates donated eggs for research. N ow, controversy has arisen regarding the $D N A$ fingerprinting reported in the study which will now be the subject of an investigation. There is great concern within the community that the image of stem cell research will be tarnished, with a corresponding negative impact on public perception and funding. 0 pponents of stem cell research would also be delighted to be given new ammunition.

O 7 D ecember last year, a petition lobbying for an investigation from 30 faculty members of $H$ wang's institution - the Seoul N ational U niversity (SN U) - was presented to SN U 's President, Un Chan Chung. Five days later SN $U$ announced that it would investigate the research at the scientist's request.

Anonymous observations questioning the paper have been posted on an Internet message board hosted by the Biological Research Information Center (BRIC)

(bric.postech.ac.kr). Supplementary fingerprinting data associated with the paper appears to show that the ES cells are genetically identical to the patients. On $7 \mathrm{D}$ ecember, the BRIC site included a critique of the D N A fingerprinting results. The height and shapes of peaks are affected by random factors and hence should not be identical. The BRIC board poster indicated that the traces for several cell lines appear to be identical to the tracesfrom the respective patients, and in other cases the background noise on the two traces looks very similar.

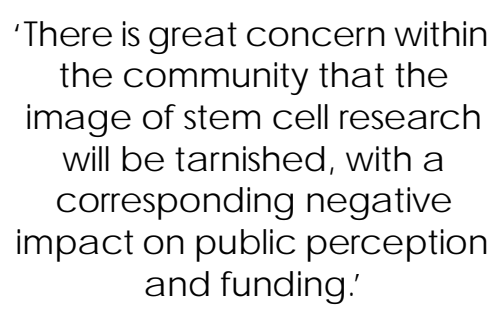

The SN U held a press conference on $12 \mathrm{D}$ ecember announcing the investigation. SNU's D ean of Research Affairs, Jung $\mathrm{H}$ ye Roe, said SNU would form an investigative committee of experts from within and outside the university. Roe also said that SN U may cooperate with the University of Pittsburgh, which started its own investigation at the request of $\mathrm{G}$ erald Schatten. Schatten was a co-author of the Sciencepaper but has asked that Soience remove his name from the paper, citing "substantial doubts about the paper's accuracy." Science declined the request on the basis that "No single author, having declared at the time of submission his full and complete confidence in the contents of the paper, can retract his name unilaterally, after publication, and while inquiries are still under way." Schatten has also referred to allegations "from someone involved in the experiments that certain elements of the report may be fabricated." 


\section{Wound-healing properties of hair follicle stem cells}

$\mathrm{H}$ air follicle stem cells could be used to help heal problematic wounds according to researchers at the University of Pennsylvania School of M edicine. Stubborn wounds, such as skin ulcers and dermatological damage in diabetes, could be more easily and quickly nursed back to full health, according to the report recently published in Nature Medicine This exciting discovery could pave the way for the development of innovative wound-healing technologies.

The idea that hair follicles contain stem cells is not new. Stem cells in the bulge area of the follicle generate new lower hair follicle cells which in turn form new hair that grows out of the skin. H owever, it has recently been suggested that these cells may be drafted in for the wound-healing process, inspiring $\mathrm{Dr}$ George Cotsarelis and his team to put the hypothesis to the test.

The epidermis naturally renews itself every few days. To see if the hair follicle stem cells are required in this process, the team first wiped-out all the hair follicle stem cells in mice, using herpes simplex virus thymidine kinase. The mice were left with a perfectly healthy epidermis that was completely bald. The virus had wiped out the follicles but not the skin proving that the cells are not required for this normal process.

"In the future, we think that we will be able to design trea tments that enhance the flow of cells from the hairfollicle to the epidermis, in the hope of enhancing wound healing."

H owever, Cotsarelis found that after damaging the skin, the hair follicle stem cells travel towards the wounded area. The bulge where these cells are produced responds quickly, by producing stem cells that migrate from deep in the follicle to the wounded region at the surface of the skin, where they take on an epidermal phenotype.

Cotsarelis and his team found that hair follicle stem cells may constitute up to a third of all normal wound coverage. The group hope that the discovery could lead to significant advances in the field of regenerative medicine: "In the future, we think that we will be able to design treatments that enhance the flow of cells from the hair follicle to the epidermis, in the hope of enhancing wound healing and treating patients with wounds".

Scientists have long acknowledged the production of stem cells from within hair follicles. H owever, Cotsarelis' team are the first to highlight just how much of the skin regeneration after wounding comes from the follicle, as opposed to the surrounding epidermis. As well as increasing our understanding of the mechanism of wound healing, the results may also have implications in treatment for hair loss.

The group's findings could be hugely influential in the way we develop future wound-healing technology

\section{Stem cell microenvironment reverses malignant melanoma}

Study provides further insight into the role of the mic roenvironment in determining cell fate.

The development of new study methods is essential in order to elucidate the mechanisms that regulate stem cell properties and determine the epigenetic effects induced by the stem cell microenvironment on the phenotype of tumor cells. Using a novel 3D model, researchers at N orthwestern University (IL, USA) have demonstrated that the microenvironments of two human embryonic stem cell (hESC) lines induced metastatic melanoma cellsto revert to a normal, skin cell-like cellswith the ability to form colonies similar to hESCs. Furthermore, the researchers demonstrated that melanoma cells were less invasive following culture on hESC microenvironments. "O ur observations highlight the potential utility of isolating the factors within the hESC microenvironment responsible for influencing tumor cell fate and reversing the cancerous properties of metastatic tumor cells, such as melanoma," stated $M$ ary JC $\mathrm{H}$ endrix, professor of pediatrics at the Feinberg School of M edicine.

To develop a method for measuring the possible epigenetic effects of the hESC microenvironment on cellular behavior and phenotype, the researchers combined a recently developed technology for culturing hESCs, under fibroblast-free conditions, with a tumor cell removal methodology, yielding an innovative $3 D$ model that facilitates multiparameter analyses. The model consists of a 3D collagen matrix preconditioned by hESC s, followed by their removal, and subsequent seeding of metastatic melanoma cells onto the embryonic microenvironment. U sing this methodology, the researchers established that the hESC microenvironment can reprogram the phenotype of aggressive melanoma cells to that of less invasive, M elan-A-producing cells. Specifically, it was demonstrated that exposure of tumor cells to $\mathrm{H} 1$ or HSF-6 hESC matrices induced a melanocyte-like phenotype with the ability to form colonies similar to hESC s.

"These findings offer a new approach to investigating the possible effects of identifying the microenvironmental factors produced by hESC s on reversing the metastatic properties of tumor cells," enthused H endrix.

Cutaneous melanoma is one of the few remaining cancers escalating in incidence, and therefore represents an increasing public health burden worldwide. Skin cancer is currently the most common malignancy in the USA, and is predicted to result in 59,580 new cases of melanoma in 2005. 


\section{UK government grants $f 100$ million to stem cell research}

In a welcome boost to the field of regenerative medicine, the $U \mathrm{~K}$ government has pledged to grant $£ 100$ million to stem cell research over the next 2 years. This follows the appointment of Sir John Pattison, former $R \& D$ director of the $D$ epartment of $\mathrm{H}$ ealth, to put into place a 10-year plan to advance this fast progressing area of the life sciences.

The introduction of the U K Stem C ell Initiative Report, launched on $D$ ecember 2 2005 , hopes to drive forward British stem cell research, with Chancellor Gordon Brown remarking "Britain should be the world's number one center for genetic and stem cell research building on our world leading regulatory regime in this area".

Although the current leader in the field, Britain may soon face some tough competition from other nations keen to get more involved in stem cell research. The U SA, South Korea, China, and Singapore are set to become firm rivals, pumping much funding into the promising area. "We are internationally competitive but, when you look around the world, others have decided to invest heavily in this area so the competition is becoming fierce", remarks Sir John who claims that Britain would need to raise an extra $£ 320$ million to $£ 520$ million

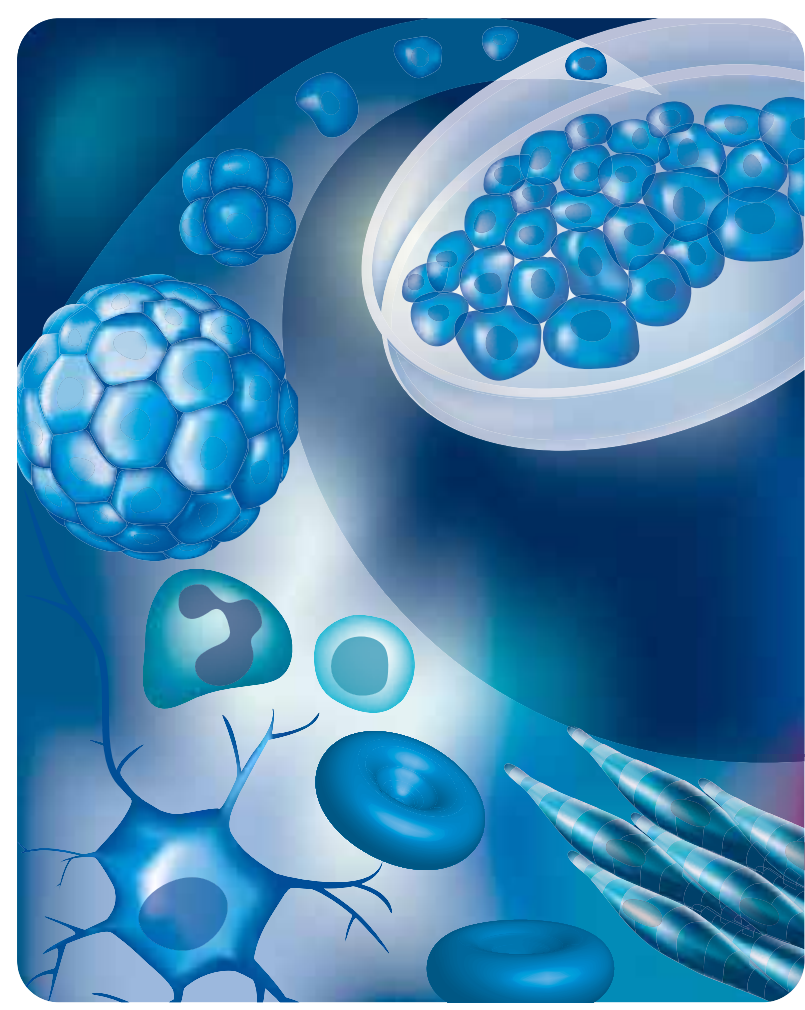
over the next 10 years, in order to keep up with the stem cell race.

The $\mathrm{H}$ ealth $\mathrm{M}$ inister Jane Kennedy also expressed her enthusiasm for the scheme: "This report provides a clear vision for maintaining the UK's position as a world leader in basic research". She further acknowledged the huge therapeutic potential for stem cell research: "It is important we continue our long-term commitment to stem cells. They have the potential to help millions of people and could lead to new treatments for serious diseases for which there is currently no cure".

The money will back "translational" research into practical uses of the most exciting advances, and will fund clinical trials within the N H S. M ost notably however, it will be used to pay for the UK Stem Cell Bank, a new organization that features later in this issue of Regenera tiveMedicine This is the first establishment of its kind in the world, and it is hoped it will help secure Britain's position as the front-runner of stem cell research.

O verall, this pledge will double the amount the UK government currently spends on stem cell research, at a time when this pioneering field is fast gaining momentum on the International circuit.

\footnotetext{
About the Bulletin Board information, please contact:

Elisa Manzotti,

Editor, Regenerative Medicine,

Future Medicine Ltd, Unitec House, 3rd Floor,

2 Albert Place, Finchley Central, London N3 1QB, UK

E-mail: e.manzotti@futuremedicine.com

Tel: +44 (0)20 8349 2033; Fax: +44 (0)20 83432313
}

The Bulletin Board highlights some of the most important events and launches in stem cell research and regenerative medicine. The editorial team welcomes suggestions for timely, relevant items. If you have newsworthy 